\title{
To compare trans-vaginal ultrasound colour doppler (TUCD) with hysteroscopy and guided endometrial biopsy in diagnosing abnormal uterine bleeding
}

\author{
Swati Choudhary $^{1}$, Syed Nawaz Ahmad ${ }^{2 *}$, Shefali Agarwal ${ }^{3}$
}

\begin{abstract}
${ }^{1}$ Department of Obstetrics and Gynecology, Deen Dayal Upadhyay Hospital, New Delhi, India
${ }^{2}$ Department of Obstetrics and Gynaecology, ESI PGIMSR, New Delhi, India

${ }^{3}$ Department of Obstetrics and Gynaecology, AIIMS, New Delhi, India
\end{abstract}

Received: 12 May 2017

Accepted: 10 June 2017

\section{*Correspondence:}

Dr. Syed Nawaz Ahmad,

E-mail: dr.syednawaz@gmail.com

Copyright: (c) the author(s), publisher and licensee Medip Academy. This is an open-access article distributed under the terms of the Creative Commons Attribution Non-Commercial License, which permits unrestricted non-commercial use, distribution, and reproduction in any medium, provided the original work is properly cited.

\begin{abstract}
Background: To compare trans-vaginal ultrasound Colour Doppler (TUCD) with hysteroscopy and guided endometrial biopsy in diagnosing abnormal uterine bleeding.

Methods: A total of 50 consecutive and haemodynamically stable patients aged more than 40 years with abnormal uterine bleeding (AUB) were included in the study. Patients with pregnancy and probable cervical malignancy were excluded. All the patients were subjected to TUCD followed by hysteroscopic directed endometrial biopsy during the follicular phase of the menstrual cycle between $7^{\text {th }}$ and $11^{\text {th }}$ day to diagnose the underlying pathology. In postmenopausal female both TUCD and hysteroscopy were performed on any day. Results of both the procedures were compared.

Results: The sensitivity and specificity of TUCD as compared to hysteroscopy in diagnosing polyp was found out to be $27.78 \%$ and $100 \%$; for fibroid $100 \%$ and $84.4 \%$; for endometrial hyperplasia $86.36 \%$ and $96.43 \%$; for endometrial carcinoma $71.43 \%$ and $100 \%$; and for endometrial atrophy $100 \%$ and $100 \%$, respectively. After application of kappa statistics, the degree of agreement between the two diagnostic procedures was found to be 0.599 which was considered to be good.

Conclusions: Conditions like fibroid, endometrial atrophy and cases of A-V malformation are better diagnosed with TUCD, while others like endometrial polyps, endometrial carcinoma are better detected on hysteroscopy. TUCD can diagnose most of the pathologies but not all, so it can be used as an adjunct to hysteroscopy to diagnose endometrial pathology, but can surely not replace hysteroscopy.
\end{abstract}

Keywords: Abnormal uterine bleeding, Colour doppler, Hysteroscopy

\section{INTRODUCTION}

In the women of child bearing age abnormal uterine bleeding (AUB) includes any change in menstrual period frequency, duration or amount of flow and intermenstrual bleeding. ${ }^{1}$ In postmenopausal women AUB includes vaginal bleeding of any cause 12 months or more after cessation of menses. ${ }^{2}$ Puberty and perimenopause are typically associated with anovulatory menstrual cycles. The immature hypothalamic-pituitary axis during puberty does not develop the necessary hormonal feedback to sustain the endometrium. Likewise, the decline of inhibin levels and rise in follicular stimulating hormone (FSH) levels reflect the loss of follicular activity and 
competence as the perimenopausal transition sets in. ${ }^{3}$ Broadly AUB has been categorised into ovulatory and anovulatory. Anovulatory bleeding is due to the failure of the development of corpus luteum and hence inadequate progesterone levels to sustain the endometrium whereas ovulatory AUB is due to some associated uterine pathology like polyp, endometrial hyperplasia, cancer, fibroid etc.

Abnormal bleeding is associated with an array of symptoms including heavy or prolonged menstrual flow, intermenstrual bleeding and frequent or delayed cycles. Women also experience social embarrassment, diminished quality of life, sexual compromise and loss of wages due to absence from work. Pain is not a common presenting symptom unless associated with passage of large blood clots.

Besides systemic, iatrogenic or age-related hormonal disharmony, an endometrial pathology (polyps, submucosal myomas, endometrial hyperplasia and endometrial carcinoma) should always be suspected. There is a battery of investigations to evaluate AUB including transvaginal ultrasound (TVUS), saline infusion sonography, hysteroscopy, transvaginal colour Doppler, MRI and endometrial biopsy. This study was intended to compare the diagnostic accuracies of transvaginal ultrasound with Colour Doppler (TUCD) and hysteroscopy with guided endometrial biopsy in AUB.

\section{METHODS}

This study was carried out in a teaching tertiary care hospital in New Delhi, India. Approval was taken from the Institutional Ethics Committee. The procedures followed were in accordance with the ethical standards of the responsible committee on human experimentation (institutional) and with the Helsinki Declaration of 1975 and revised in 2008. Fifty consecutive patients aged more than 40 years with AUB attending the outpatient clinic and willing for participation in the study were included after informed consent.

Patients with bleeding due to pregnancy complications, known cases of endometrial cancer, pelvic inflammatory diseases, suspected cervical malignancy, adenexal masses and haemodynamic instability were not included in the study cohort. A thorough work-up including historical review, general physical and systemic examination and various investigations to rule out systemic causes of AUB were carried out. All patients were subjected to TUCD during the follicular phase of the menstrual cycle between the $7^{\text {th }}$ and $11^{\text {th }}$ day using a $6.5 \mathrm{MHz}$ vaginal transducer (HDI 4000) equipped with colour and pulsed Doppler.

Endometrium was classified as normal or abnormal based on the endometrial thickness, average values of the pulsatility and resistivity indices of bilateral uterine arteries and the various lesions identified. After bleeding stopped, patients were subjected to hysteroscopic directed endometrial biopsy on $7^{\text {th }}$ to $11^{\text {th }}$ day of menstrual cycle using $8 \mathrm{~mm}$ operative hysteroscope. In postmenopausal females, both TUCD and hysteroscopy were performed on any planned day after bleeding stopped. Endometrial biopsy was taken with a biopsy needle. Endometrium was classified as normal or abnormal depending upon hysteroscopic findings and confirmed by histopathology.

\section{Statistical analysis}

Statistical measures like sensitivity, specificity, positive predictive value (PPV), negative predictive value (NPV), false positive rate (FPR), false negative rate (FNR) were used. Kappa statistics was used to calculate the degree of agreement between the two diagnostic tools. $[\mathrm{k}<0.4$ : poor agreement; $\mathrm{k}=0.4-0.75$ : good agreement; $\mathrm{k}>0.75$ : excellent agreement

\section{RESULTS}

The mean age of study population was 47.04 years. The most common presenting complaint with which patients presented was found to be heavy menstrual bleeding (42\%), followed by frequent heavy bleeding (18\%). TUCD diagnosed endometrial pathology in $80 \%$ patients. (Figure 1).

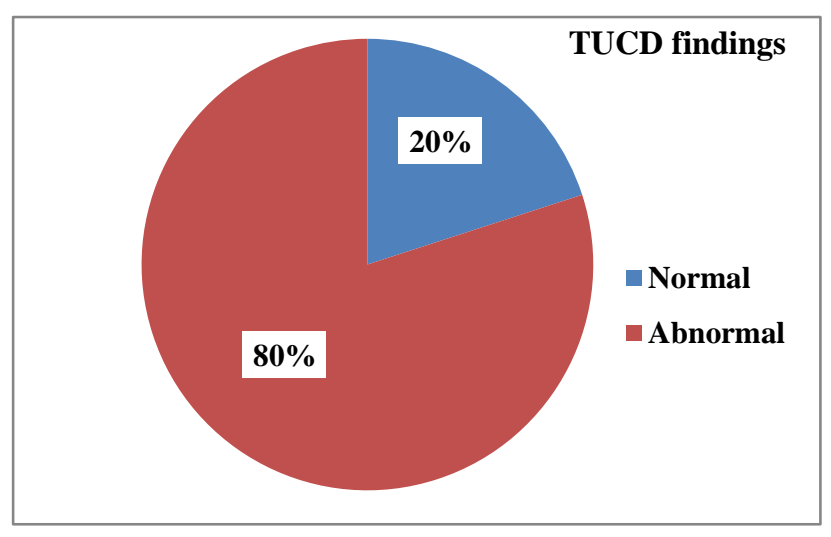

Figure 1: Pie diagram showing relative percentage of cases with some endometrial pathology as diagnosed by TUCD.

Endometrial hyperplasia was the most common endometrial pathology detected by TUCD. Other findings that were found by Doppler are listed in Table 1.

The mean PI (pulsatility index) value was found out to be $1.433 \pm 0.293$ while the mean RI (resistivity index) was found out to be $0.534 \pm 0.0262$. The mean endometrial thickness was $12.792 \pm 5.9119 \mathrm{~mm}$ (Table 2).

Hysteroscopic findings: Endometrial hyperplasia was the most common abnormality detected by hysteroscopic evaluation (24\% of cases), followed by polyp alone and polyp along with hyperplasia. Two cases each of fibroid with endometrial hyperplasia, and polyp with suspected carcinoma endometrium were detected. 
Table 1: TUCD findings in the study group.

\begin{tabular}{|lll|}
\hline Colour Doppler findling & Frequency (n) & $\%$ \\
\hline Normal (1) & 10 & 20 \\
\hline Polyp (2a) & 4 & 8 \\
\hline Fibroid (2b) & 6 & 12 \\
\hline $\begin{array}{l}\text { Endometrial hyperplasia } \\
\text { (2c) }\end{array}$ & 13 & 26 \\
\hline Endometrial carcinoma (2d) & 5 & 10 \\
\hline Atrophic endometrium (2e) & 4 & 8 \\
\hline A-V malformation (2f) & 1 & 2 \\
\hline $2 \mathrm{a}+2 \mathrm{c}$ & 1 & 2 \\
\hline $2 \mathrm{~b}+2 \mathrm{c}$ & 6 & 12 \\
\hline Total & 50 & 100 \\
\hline
\end{tabular}

Table 2: Pulsatility index, resistivity index and endometrial thickness as calculated by TUCD.

\begin{tabular}{|llll|}
\hline & $\begin{array}{l}\text { Pulsatility } \\
\text { Index (PI) }\end{array}$ & $\begin{array}{l}\text { Resistivity } \\
\text { Index } \\
(\mathrm{RI})\end{array}$ & $\begin{array}{l}\text { Endometrial } \\
\text { Thickness } \\
(\mathrm{ET})\end{array}$ \\
\hline $\begin{array}{l}\text { Frequency } \\
\text { (n) }\end{array}$ & 50 & 50 & 50 \\
\hline $\begin{array}{l}\text { Minimum } \\
\text { value }\end{array}$ & 1.09 & 0.47 & 2.0 \\
\hline $\begin{array}{l}\text { Maximum } \\
\text { value }\end{array}$ & 2.66 & 0.58 & 26.0 \\
\hline Mean & 1.4334 & 0.5344 & 12.792 \\
\hline $\begin{array}{l}\text { S.D. } \\
\text { Median }\end{array}$ & 0.29335 & 0.0262 & 5.9119 \\
\hline
\end{tabular}

Hysteroscopy could recognise some endometrial abnormality in $88 \%$ patients with AUB (Table 3). Colour Doppler indices associated with various hysteroscopic findings is shown in Table 4. As can be inferred from the table that fibroid and polyp exhibit a high resistance flow while as carcinoma endometrium shows a low resistance flow. Histopathology revealed simple endometrial hyperplasia as the commonest finding (38\%) followed by secretory endometrium (34\%). Endometrial carcinoma was diagnosed in $8 \%$ patients on histopathology (Figure 2).

Doppler results were compared to hysteroscopy, keeping hysteroscopic findings as gold standard. The sensitivity of TUCD in diagnosing endometrial polyp was almost $27 \%$ while its specificity was $100 \%$ with a positive predictive value (PPV) of $100 \%$ and negative predictive value (NPV) of $71.1 \%$. The false positive rate (FPR) was $0 \%$, while the false negative rate (FNR) $72.2 \%$.

Table 3: Hysteroscopic examination findings in the study population.

\begin{tabular}{|lll|}
\hline & Frequency (n) & $\%$ \\
\hline Normal (1) & 6 & 12 \\
\hline Polyp (2a) & 8 & 16 \\
\hline Fibroid (2b) & 3 & 6 \\
\hline $\begin{array}{l}\text { Endometrial hyperplasia } \\
\text { (2c) }\end{array}$ & 12 & 24 \\
\hline $\begin{array}{l}\text { Carcinoma endometrium } \\
\text { (2d) }\end{array}$ & 5 & 10 \\
\hline Atrophic endometrium (2e) & 4 & 8 \\
\hline A-V malformation (2f) & 0 & 0 \\
\hline 2a+2c & 8 & 16 \\
\hline 2a+2d & 2 & 4 \\
\hline 2b+2c & 2 & 4 \\
\hline Total & 50 & 100 \\
\hline
\end{tabular}

These observations showed that Colour Doppler could be used as a diagnostic tool for diagnosing polyps, but not as a screening tool. Sensitivity of Colour Doppler for diagnosing fibroids was $100 \%$. Specificity, PPV and NPV were found out to be $84.4 \%, 41.67 \%$ and $100 \%$ respectively.

Table 4: Colour doppler indices associated with various hysteroscopic findings.

\begin{tabular}{|c|c|c|c|c|c|c|}
\hline TUCD Indices & $\begin{array}{l}\text { Patients with normal } \\
\text { hysteroscopy }\end{array}$ & Polyp & Fibroid & $\begin{array}{l}\text { Endometrial } \\
\text { hyperplasia }\end{array}$ & $\begin{array}{l}\text { Carcinoma } \\
\text { endometrium }\end{array}$ & $\begin{array}{l}\text { Endometrial } \\
\text { atrophy }\end{array}$ \\
\hline $\mathrm{PI}^{*}$ & $1.25 \pm 1.09$ & $1.39 \pm 0.22$ & $1.45 \pm 0.07$ & $1.27 \pm 0.18$ & $1.29 \pm 0.06$ & $2.16 \pm 0.36$ \\
\hline $\mathrm{RI}^{*}$ & $0.54 \pm 0.02$ & $0.55 \pm 0.01$ & $0.56 \pm 0.01$ & $0.54 \pm 0.01$ & $0.48 \pm 0.01$ & $0.51 \pm 0.01$ \\
\hline ET $^{*}$ & $8.89 \pm 2.74$ & $10.34 \pm 3.26$ & $7.63 \pm 0.85$ & $16.5 \pm 2.19$ & $23.2 \pm 3.11$ & $2.3 \pm 0.47$ \\
\hline
\end{tabular}

*PI: Pulsatility index, RI: Resistivity index, ET: Endometrial thickness

FPR and FNR were $15.6 \%$, and $0 \%$ respectively. Extrapolation of these findings suggested that Colour Doppler could be used as a fairly good tool to diagnose as well as screen fibroids. The sensitivity and specificity found in case of endometrial hyperplasia were $86.36 \%$ and $96.43 \%$, respectively. PPV and NPV were found out to be $95 \%$ and $90 \%$, respectively. For detecting endometrial carcinoma, the sensitivity was found to be
$71.43 \%$, while, specificity was $100 \%$. PPV was $100 \%$ and NPV was $95.5 \%$. FPR was $0 \%$ and FNR $28.57 \%$. From this it could be inferred that TUCD was a better technique to diagnose endometrial carcinoma but not that good a technique to screen for carcinoma, as many cases of carcinoma could go undetected by TUCD alone. The sensitivity, specificity, PPV and NPV of TUCD to diagnose endometrial atrophy were $100 \%$ each making it 
as good a diagnostic and screening tool as hysteroscopy. FPR and FNR were 0\% each in these cases.

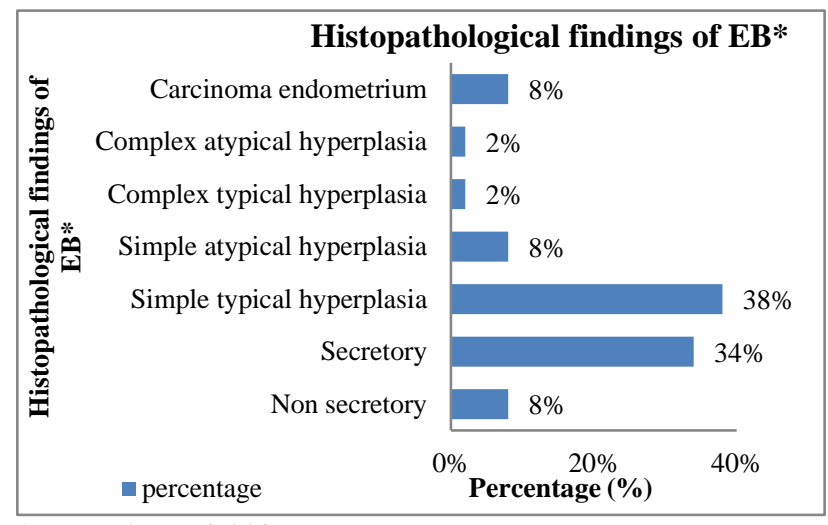

*EB: endometrial biopsy

\section{Figure 2: Histopathological findings of the endometrial biopsy.}

This value of kappa $(\mathrm{k})$ came out to be 0.559 which signified a good agreement between the results of TUCD and hysteroscopy.

\section{DISCUSSION}

TUCD imaging facilitates the visualisation of small vessels in the utero-ovarian circulation and measurement of impedance to blood flow in this vascular tree. Hysteroscopy is considered as the gold standard technique for the evaluation of endometrial pathology for long.

In present study, the mean age of the participants was 47.0 \pm 6.2 years with only one third being literate. Majority of the participants were of $3^{\text {rd }}$ or more parity with only 2 nulliparous patients both of whom presented as post-menopausal bleeding and were eventually diagnosed as endometrial cancer which high lightened the fact that nulliparous women are at high risk for endometrial cancer.

In present study, most common symptom was heavy menstrual bleeding (42\%) which was comparable to the study by Jaiswar et al in $2006(40 \%){ }^{4}$

TUCD could diagnose endometrial polyp in $4(8 \%)$ cases while on hysteroscopy polyp was demonstrated in 8 (16\%) patients. The basic principle that leads to the diagnosis of polyp by TUCD is demonstration of a vascular pedicle. The use of power Doppler with better resolution may improve the diagnostic accuracy of TUCD for polyps. ${ }^{5}$ Although our study demonstrated low resistance flow in malignant lesions but neither hysteroscopy nor TUCD can establish the benign or malignant nature of these polypoidal lesions. Our study results revealed that TUCD was a good diagnostic tool for polyps with $100 \%$ specificity but lacks the sensitivity to be used as a screening device as supported by the studies of Pascual A et al and Yela DA et al. ${ }^{6,7}$

TUCD picked up fibroid uterus in 12 cases out of which 6 patients had both fibroid and endometrial hyperplasia. Hysteroscopy could demonstrate only 5 cases of fibroid uterus out of which two cases were complicated by endometrial hyperplasia as well. It was found that hysteroscopy readily picked up the submucous myomas but could not diagnose intra-mural myomas except the large ones which distorted uterine cavity where their presence could be suspected. In a study by Farquhar $\mathrm{C}$ et al the diagnostic accuracy for submucous uterine fibroids was better by hysteroscopy and saline hysterosonography as compared to transvaginal ultrasonography. ${ }^{8}$

Hysteroscopy comes with the added advantage of resection of the submucous fibroids in the same sitting. ${ }^{9,10}$ While studying the blood flow patterns of the fibroids by TUCD a decrease in the impedance to the flow was observed in addition to a constant diastolic flow to the myoma. These findings were similar to the study by Kurjak A et al. ${ }^{11}$

TUCD demonstrated endometrial hyperplasia in $26 \%$ patients. The mean endometrial thickness recorded was 16.5 \pm 2.19 . Hysteroscopy could prompt presence of hyperplastic endometrium in $24 \%$ patients. However, on histopathological examination endometrial hyperplasia was diagnosed in $50 \%$ patients. Ten percent patients were diagnosed to have atypical hyperplasia while the rest had simple hyperplastic endometrium. These findings suggested that although TUCD and hysteroscopy could diagnose endometrial hyperplasia, both lack accuracy and histopathology is necessary specially to diagnose the cases with atypical changes because of the associated risks of malignant transformation. As per the previous studies too it seems logical that a patient with AUB be subjected to non-invasive TUCD to know the endometrial thickness and colour flow patterns following which the patient can undergo hysteroscopy and directed biopsy, shall the need be felt. ${ }^{6,12}$

Present study found that TUCD was as good a screening and diagnostic tool for endometrial atrophy as hysteroscopy with a sensitivity, specificity, PPV, NPV of $100 \%$ each. Other international studies also show that endo-vaginal ultrasound is a fairly good tool for diagnosis of atrophic endometrium and that below a cut off limit of $5 \mathrm{~mm}$ thick endometrium, the risk of malignancy being very low, endo-vaginal ultrasound may be the lone investigation needed. ${ }^{13}$

Uterine arteriovenous malformation constitutes a rare cause of refractory AUB. In our study, we came across one such case which was diagnosed by TUCD but hysteroscopy couldn't detect any abnormality. There are case reports in literature which highlight Colour Doppler 
as the primary non-invasive diagnostic test for arteriovenous malformations. ${ }^{14-16}$

Five cases of endometrial carcinoma were predicted by TUCD. All the cases exhibited a low resistance flow. The mean endometrial thickness in these cases was $23.2 \pm 3.11 \mathrm{~mm}$. Hysteroscopy also predicted the same number of cases but histopathology confirmed the diagnosis in only 4 cases. The fifth cases were diagnosed as complex hyperplasia with atypia. Although TUCD can diagnose endometrial carcinoma with a fair degree of accuracy, it can't be relied upon completely and can't be used as the sole screening tool keeping in mind the seriousness of the condition. Also, the study parameters like thickened endometrium and low resistance flow can also be seen in patients on hormone therapy or tamoxifen therapy for breast cancer. There have been research studies in the past which show that Colour Doppler ultrasound can predict malignant endometrial disease. ${ }^{5,17}$ However, hysteroscopy and directed biopsy form the gold standard diagnostic modality in contemporary medicine. ${ }^{18,19}$ Although there were concerns regarding the spread of endometrial cancer by hysteroscopy, the ideology has been refuted by current research. ${ }^{20}$

\section{CONCLUSION}

Hysteroscopy is considered as the gold standard for the evaluation of endometrial pathology. On comparing Transvaginal Colour Doppler findings with those of hysteroscopy, it was observed that there was a good agreement between the results of the two techniques. Transvaginal Colour Doppler can also be used as fairly good investigation technique for the diagnosis endometrial pathology.

Funding: No funding sources

Conflict of interest: None declared

Ethical approval: The study was approved by the Institutional Ethics Committee

\section{REFERENCES}

1. Livingstone M, Fraser IS. Mechanisms of abnormal uterine bleeding. Hum Reprod Update. 2002;8:60-7.

2. Lethaby A, Farquhar C, Sarkis A, Roberts H, Jepson $\mathrm{R}$, Barlow D. Hormone replacement therapy in postmenopausal women: endometrial hyperplasia and irregular bleeding. Cochrane Database Syst Rev. 2003;(4):CD000402.

3. Bardley LD. Abnormal uterine bleeding. The Nurse Practitioner. 2005;30(10):38-49.

4. Jaiswar SP, Sachan R, Srivastava PK. A comparative diagnostic evaluation of hysteroscopy, transvaginal ultrasonography and histopathological examination in cases of abnormal uterine bleeding. J Obs Gynaecol India. 2006;56(3):240-3.

5. Alcazar JL, Castillo G, Minguez JA, Galan MJ. Endometrial blood flow mapping using transvaginal power Doppler sonography in women with postmenopausal bleeding thickened endometrium. Ultrasound Obstet Gynecol. 2003;21:583-8.

6. Pascual A, Graupera B, Tresserra F, Ubeda A, Hereter L, Rodriguez I et al. Color Doppler transvaginal ultrasound for detecting intrauterine disorders in patients with abnormal uterine bleeding; Gynaecol Perinatol. 2005;14(4):157-60.

7. Yela DA, Ravacci SH, Monteiro IM, Pereira KC, Gabiatti JR. Comparative study of transvaginal sonography and outpatient hysteroscopy for detection of pathologic endometrial lesions in postmenopausal women. Rev Assoc Med Bras. 2009; 55(5):553-6.

8. Farquhar C, Ekeroma A, Furness S, Arroll B. A systematic review of transvaginal ultrasonography, sonohysterography and hysteroscopy for the investigation of abnormal uterine bleeding in premenopausal women. Acta obstetricia et gynecologica Scandinavica. 2003;82(6):493-504.

9. Neuwirth RS. Hysteroscopic management of symptomatic submucous fibroids. Obstetrics Gynecol. 1983;62(4):509-10.

10. Wamsteker K, Emanuel MH, de Kruif JH. Transcervical hysteroscopic resection of submucous fibroids for abnormal uterine bleeding: results regarding the degree of intramural extension. Obstetr Gynecol. 1993;82(5):736-40.

11. Kurjak A, Shalan H, Kupesic S, Predanic M, Zalud I, Breyer B, et al. Transvaginal color Doppler sonography in the assessment of pelvic tumor vascularity. Ultrasound in obstetrics gynecology: the official journal of the International Society of Ultrasound in Obstetr Gynecol. 1993;3(2):137-54.

12. Revel A, ShushanA. Investigation of infertile couple: hysteroscopy with endometrial biopsy is the gold standard investigation for abnormal uterine bleeding. Human Reprod. 2002;17:1947-9.

13. Gull B, Carlsson S, Karlsson B, Ylöstalo P, Milsom I, Granberg S. Transvaginal ultrasonography of the endometrium in women with postmenopausal bleeding: Is it always necessary to perform an endometrial biopsy? Am J Obstet Gynecol. 2000; 182:509-15.

14. Fleming $\mathrm{H}$, Ostor AG, Pickel H, Fortune DW. Arteriovenous malformations of the uterus. Obstet Gynecol. 1989;73:209-14.

15. Flynn MK, Levine D. The noninvasive diagnosis and management of a uterine arteriovenous malformation. Obstet Gynecol. 1996;88(4.2):650-2.

16. Cura M, Martinez N, Cura A, Dalsaso TJ, Elmerhi F. Arteriovenous malformations of the uterus. Acta Radiol. 2009;50:823-9.

17. Epstein E, Skoog L, Isberg PE. An algorithm including results of gray-scale and power Doppler ultrasound examination to predict endometrial malignancy in women with postmenopausal bleeding. Ultrasound Obstet Gynecol. 2002;20:3706.

18. Zhu HL, Liang XD, Wang JL, Cui H, Wei LH. Hysteroscopy and directed biopsy in the diagnosis of 
endometrial carcinoma. Chin Med J (Engl). 2010;123:3524-8.

19. Koutlaki N, Dimitraki M, Zervoudis S, Skafida P, Nikas I, Mandratzi $\mathbf{J}$ et al. Hysteroscopy and endometrial cancer. Gynecol Surg. 2010;7:335-41.

20. Soucie JE, Chu PA, Ross S. The risk of diagnostic hysteroscopy in women with endometrial cancer. Am J Obstet Gynecol. 2012;207:71.e1-5.
Cite this article as: Choudhary S, Ahmad SN, Agarwal S. To compare trans-vaginal ultrasound colour doppler (TUCD) with hysteroscopy and guided endometrial biopsy in diagnosing abnormal uterine bleeding. Int J Reprod Contracept Obstet Gynecol 2017;6:3035-40. 